\title{
Retraction: Lipid metabolism disturbances and AMPK activation in prolonged propofol-sedated rabbits under mechanical ventilation
}

\author{
Wei JIANG\#, Zheng-bo YANG\#", Quan-hong ZHOU, Xiang HUAN, Li WANG* \\ Department of Anesthesiology, Shanghai Sixth Municipal Hospital, Shanghai Jiaotong University, Shanghai 200233, China
}

\begin{abstract}
Aim: To explore the mechanisms underlying the propofol infusion syndrome (PRIS), a potentially fatal complication during prolonged propofol infusion.

Methods: Male rabbits under mechanical ventilation through endotracheal intubation were divided into 3 groups ( $n=6$ for each) that were sedated with 1\% propofol (Group P), isoflurane (Group I) or isoflurane while receiving 10\% intralipid (Group II), respectively. Blood biochemical parameters were collected at $0,6,12,18,24$, and 30-36 h after the initiation of treatments. The hearts were removed out immediately after the experiments, and the level of tumor necrosis factor (TNF)- $\alpha$ in the hearts were studied using immunohistochemistry. AMP-activated protein kinase (AMPK) and phospho-AMPK in the hearts were assessed using Western blotting. Results: The mortality rate was 50\% in Group P, and 0\% in Groups I and II. The serum lipids and liver function indices in Group P were significantly increased, but moderately increased in Group II. Significant decreases in these indices were found in Groups I. All the groups showed dramatically increased release of creatine kinase (CK). Intense positive staining of TNF- $\alpha$ was found in all the heart samples in Group P, but only weak and neglectful staining was found in the hearts from Group II and Group I, respectively. AMPK phosphorylation was significantly increased in the hearts of Group P.

Conclusion: Continuous infusion of large dose of propofol in rabbits undergoing prolonged mechanical ventilation causes hyperlipidemia, liver dysfunction, increased CK levels, AMPK activation and myocardial injury. The imbalance between energy demand and utilization may contribute to PRIS.
\end{abstract}

Keywords: propofol; propofol infusion syndrome (PRIS); sedation; isoflurane; intralipid; tumor necrosis factor alpha; AMPK

Acta Pharmacologica Sinica (2012) 33: 27-33; doi: 10.1038/aps.2011.155; published online 12 Dec 2011

\section{Introduction}

Propofol is the most commonly used intravenous anesthetic, and it has gained widespread popularity because of its rapid onset and short duration of recovery. However, a potentially fatal complication after prolonged propofol infusion has been described in an increasing number of reports ${ }^{[1-3]}$. This complication has been termed propofol infusion syndrome (PRIS) ${ }^{[4]}$ and includes progressive myocardial failure, bradycardia, lactic acidosis, rhabdomyolysis, hyperkalemia, lipemia, acute renal failure, and death. Unfortunately, little data on the mechanisms of PRIS are available.

PRIS resembles mitochondrial cytopathies and acquired carnitine deficiency ${ }^{[5,6]}$. Malonyl-carnitine, C5-acylcarnitine,

\footnotetext{
\# These authors contributed equally to this work.

* To whom correspondence should be addressed.

E-mail liwang1118@hotmail.com

Received 2011-07-14 Accepted 2011-09-23
}

creatine kinase, troponin $\mathrm{T}(\mathrm{TnT})$ and myoglobin levels are increased in pediatric PRIS, which is consistent with impaired fatty acid oxidation due to a reduction of the mitochondrial entry of long-chain acylcarnitine esters and the failure of the respiratory chain. High concentrations of propofol impair mitochondrial respiration in rat brain synaptosomes (Marion et al citation ${ }^{[6]}$. An uncoupling of oxidative phosphorylation due to an increase in the proton permeability of the inner mitochondrial membrane has been observed in isolated rat liver mitochondria ${ }^{[7]}$. Propofol uncouples oxidative phosphorylation and inhibits the electron transport chain, which decreases mitochondrial energy production, in isolated perfused guinea pig hearts ${ }^{[8]}$. The mitochondrial damage that is associated with propofol infusion is characterized by an imbalance between energy demand and utilization, which is a key pathogenetic mechanism in PRIS. AMP-activated protein kinase (AMPK) is also a primary regulator of the cellular response to lowered ATP levels in eukaryotes ${ }^{[9,10]}$. AMPK is 
a serine/threonine protein kinase in the Snf1/AMPK protein kinase family ${ }^{[11]}$. AMPK activity requires the phosphorylation of the alpha subunit on $\mathrm{Thr}^{172}$ in its activation loop by one or more upstream kinases $(\mathrm{AMPKKs})^{[11]}$. AMPK phosphorylation downregulates ATP-consuming processes, such as the synthesis of fatty acids, cholesterol, and protein, but it also upregulates ATP-producing catabolic pathways, such as fatty acid oxidation and glucose uptake ${ }^{[11,12]}$. However, the role of AMPK in PRIS is not known.

This study examined the effects of a prolonged infusion of large doses of $1 \%$ propofol on the cardiac morphology and blood biochemical profiles in rabbits undergoing prolonged mechanical ventilation, and determined the role of AMPK signaling in PRIS. Our results demonstrated that the infusion of a large dose of propofol induced an emergent life-ending syndrome in rabbits that was consistent with PRIS and an increase in the phosphorylation of AMPK at $\mathrm{Thr}^{172}$.

\section{Materials and methods Materials}

Injections of $1 \%$ propofol $(w / v)$ and $10 \%$ intralipid were purchased from AstraZeneca Pharmaceuticals (AstraZeneca, Cheshire, UK). Isoflurane was obtained from Baxter International, Inc (Deerfield, IL, USA). Antibodies against phosphoAMPK at $\mathrm{Thr}^{172}$ and a-AMPK were purchased from Cell Signaling Technology, Inc (China), and anti-TNF-a antibody was purchased from Santa Cruz Biotechnology, Inc (Santa Cruz, CA, USA). ECL reagent was purchased from Pierce Thermo Fisher Scientific, Inc (Rockford, IL, USA). Other chemical agents were purchased from Sigma (St Louis, MO, USA).

\section{Animals}

Healthy male New Zealand rabbits weighing $2.5-3.0 \mathrm{~kg}$ at 3 months of age were used in this study $(n=18)$. The rabbits were exposed to a 12-h light/dark cycle and received food and water ad libitum.

The animals were premedicated with a mixture of xylazine $(50 \mu \mathrm{g} / \mathrm{kg}, \mathrm{im})$ and atropine $(50 \mu \mathrm{g} / \mathrm{kg}$, im) after an overnight fast and anesthetized with ketamine hydrochloride $(0.05 \mathrm{~g} / \mathrm{kg}$, im) for endotracheal intubation $20 \mathrm{~min}$ later. Artificial ventilation was initiated using a pressure ventilator (ALC-V8S, Alcott Biotech Co, Ltd, Shanghai, China). The initial settings (flow rate, $8 \mathrm{~L} / \mathrm{min}$; respiratory rate, 20-25 breath/min; peak inspiratory pressure, $12 \mathrm{cmH}_{2} \mathrm{O}$; and inspiration triggering, $-2 \mathrm{cmH}_{2} \mathrm{O}$ ) provided a tidal volume of approximately 6-8 $\mathrm{mL} / \mathrm{kg}$, and these settings were adjusted to maintain an arterial $P_{\text {acO2 }}$ between 30 and $40 \mathrm{mmHg}$ if required. The initial $40 \% \mathrm{FIO}_{2}$ (fraction of inspired $\mathrm{O}_{2}$ ) was adjusted to achieve a $P_{\mathrm{aO} 2}$ over $90 \mathrm{mmHg}$ or an $\mathrm{SpO}_{2}>95 \%$.

A 5-lead electrocardiogram invasive arterial blood pressure, heart rate, $\mathrm{SpO}_{2}$, respiratory rate and body temperature were continuously monitored (Hewlett Packard M3046A/Viridia). The levels of electrolytes and glucose were assessed every $4 \mathrm{~h}$ (Hitachi 7600, Japan). An $\mathrm{NaHCO}_{3}$ solution was administered iv if metabolic acidosis occurred (20 mL NaHCO $5 \%$ was administered within $1 \mathrm{~h}$ if $\mathrm{pH}<7.25$ and $\left.\mathrm{HCO}_{3}{ }^{-}<15 \mathrm{mEq} / \mathrm{L}\right)$.
Electrolytes and glucose levels were corrected if necessary. A dose of 300 IU of heparin sodium per kilogram of bodyweight was used via subcutaneous injection every $12 \mathrm{~h}$ for thrombosis prophylaxis. A central ear artery and two marginal ear veins were catheterized (20-gauge polyethylene catheter) to provide intra-arterial and IV access, respectively. The animals were placed in a supine position on a heated operation table and covered with an isothermic blanket to maintain normothermia. The urinary bladder was catheterized using an $8 \mathrm{CH}$ Foley catheter to facilitate urine collection. Animals received either Ringer's lactated saline solution iv for electrolyte and fluid support or dextrose $5 \%$ saline during the experiment when glucose levels decreased to $<0.8 \mathrm{~g} / \mathrm{L}$ (normal range $0.75-1.40$ $\mathrm{g} / \mathrm{L}$ ). Animals ( $n=6 /$ group) were randomly assigned to sedation with 1\% propofol (Group P), isoflurane (Group I), or isoflurane while receiving 10\% intralipid (Group II). The Shanghai Jiaotong University Animal Care and Use Committee approved all experimental procedures and protocols, and all studies were performed in accordance with the National Research Council (US) Institute Guidelines for Laboratory Animal Care.

\section{Measurement of blood biochemical variables}

Venous blood samples were collected in test tubes and centrifuged at $3000 \times g$ for $10 \mathrm{~min}$ to obtain serum. The following variables were measured (ILAB 600 Analyser, Lichtenfels, Germany): potassium, sodium, glucose, urea, creatinine, lactate dehydrogenase (LDH), total protein content, albumins, total bilirubin, direct bilirubin, glutamic oxaloacetic transaminase (GOT), glutamic pyruvic transaminase (GPT), cholesterol, triglycerides, and creatine kinase (CK).

\section{Histological examination}

Animals were exsanguinated after the termination of experiments, and the hearts were quickly excised and divided into two parts. One half was fixed in 10\% neutral-buffered formaldehyde, embedded in paraffin wax, sectioned serially at 4 $\mu \mathrm{m}$, and stained with hematoxylin-eosin (H\&E). Immunohistochemical investigation of heart samples was performed utilizing an anti-TNF-a monoclonal antibody. Cardiac tissues slices were subjected to histological examination under an Olympus BX microscope by two independent researchers in a blinded manner.

The other half of the heart was rapidly frozen on dry ice. Frozen tissue was homogenized in ice-cold lysis buffer containing $10 \mathrm{mmol} / \mathrm{L}$ Tris, $100 \mathrm{mmol} / \mathrm{L} \mathrm{NaCl}, 1 \mathrm{mmol} / \mathrm{L}$ EDTA, $1 \mathrm{mmol} / \mathrm{L}$ EGTA, $1 \mathrm{mmol} / \mathrm{L} \mathrm{NaF}, 20 \mathrm{mmol} / \mathrm{L} \mathrm{Na}_{4} \mathrm{P}_{2} \mathrm{O}_{7}, 2$ $\mathrm{mmol} / \mathrm{L} \mathrm{Na}_{3} \mathrm{VO}_{4}, 0.1 \%$ SDS, $0.5 \%$ sodium deoxycholate, $1 \%$ Triton X-100, 10\% glycerol, $10 \mathrm{mg} / \mathrm{L}$ leupeptin, $60 \mathrm{mg} / \mathrm{L}$ aprotinin, and $1 \mathrm{mmol} / \mathrm{L}$ phenylmethanesulfonyl fluoride. Cell lysates were centrifuged at $16000 \times g$ for $10 \mathrm{~min}$, and the supernatants were collected.

\section{Immunoblotting}

Western blotting (WB) analysis was performed on total cell lysates. Protein concentrations were measured using the Brad- 
ford protein assay ${ }^{[13]}$. All samples were mixed with Laemmli sample buffer [sodium dodecyl sulfate (SDS)] and placed in a boiling water bath for $5 \mathrm{~min}$. Proteins $(50 \mu \mathrm{g})$ were resolved in $10 \%$ SDS-polyacrylamide gels, transferred to nitrocellulose, and incubated overnight with primary antibodies against phospho-AMPK at $\mathrm{Thr}^{172}$ and a-AMPK (1:2000). Immunoblots were developed using horseradish peroxidase-conjugated goat antimouse or goat antirabbit immunoglobulin G (1:3000). Protein bands were visualized using the ECL reagent (Pierce Thermo Fisher Scientific, Inc, Rockford, IL, USA), and density was quantified using the Scion Image software (Scion Corp, Frederick, MD, USA).

\section{Experimental protocols}

Protocol 1 (Group P): effect of prolonged 1\% propofol sedation on rabbits under mechanical ventilation

Animals were sedated using a continuous propofol infusion (1\% Diprivan, AstraZeneca, Cheshire, UK) for $36 \mathrm{~h}$ or until death. Propofol was administered at the first signs of awakening from general anesthesia (restoration of corneal reflex) and at an initial rate (IR) of $10 \mathrm{mg} \cdot \mathrm{kg}^{-1} \cdot \mathrm{h}^{-1}$ using an infusion pump (Baxter AS40A, 1800 Williamson Ct Louisville, KY, USA). The IR was adjusted in $5 \mathrm{mg} \cdot \mathrm{kg}^{-1} \cdot \mathrm{h}^{-1}$ steps to maintain the desired level of sedation when necessary. The level of sedation was assessed using a corneal reflex response every $30 \mathrm{~min}$; earlier assessments were performed only when clinical signs of awakening were observed (25\% increase in heart rate and/or arterial blood pressure from the previous measurement, any increase in respiratory rate from the ventilator setting). The criteria for the desired level of sedation are listed in Table 1. The IR was reduced if necessary in $5 \mathrm{mg} \cdot \mathrm{kg}^{-1} \cdot \mathrm{h}^{-1}$ steps every 15 min until the initial signs of awakening were observed to avoid propofol overdose. The IR was returned to the previously identified safe dose to maintain an adequate level of sedation.

Table 1. Criteria for reflex response evaluation indicating light level of sedation in mechanically ventilated rabbits.

Reflex

Palpebral

Corneal

Swallowing

-, loss; +, preservation.

Protocol 2 (Group I): Effect of isoflurane sedation on rabbits undergoing prolonged mechanical ventilation

Animals were sedated using an alternative anesthetic, isoflurane (Baxter International, Inc, Deerfield, IL, USA), for $36 \mathrm{~h}$ with a conventional vaporizer at an initial rate of $1 \%$ to distinguish the effects of propofol sedation from the effects of prolonged mechanical ventilation. The doses were adjusted if necessary to maintain a light level of sedation (Table 1).
Protocol 3 (Group II): Effect of 10\% intralipid on isofluranesedated rabbits undergoing prolonged mechanical ventilation

One group of animals was sedated using the inhaled anesthetic, isoflurane, during 10\% intralipid administration for $36 \mathrm{~h}$ to distinguish the effect of a $1 \%$ propofol infusion from lipid vehicle (10\% intralipid) in sedated rabbits under mechanical ventilation. The initial isoflurane concentration was $1 \%$, and this concentration was adjusted if necessary to maintain a light level of sedation. Intralipid (10\%) was infused continuously at a rate that was equal to the average hourly $1 \%$ propofol infusion rate in Group P.

\section{Statistical analysis}

Data from the blood biochemical analysis are presented as the mean $\pm S D$. These data were subjected to a repeated measures analysis of variance. The differences between the mean values within time points in the same group were tested using the Bonferroni test, and differences between groups for the same time point were compared using the Student's $t$-test. A probability of $P<0.05$ was considered statistically significant. The results shown in the blots are representative of $\geq 3$ independent experiments and represent the mean \pm SD. Densitometry data were analyzed using a 1-way ANOVA with a significant level of $P<0.05$.

\section{Results}

\section{Mortality rate, blood biochemistry, and blood pressure}

The mortality rate in Group P was 50\%; one animal survived for $30 \mathrm{~h}$ and the other animals survived for $34 \mathrm{~h}$. No deaths were observed in Groups I and II. The deterioration of the clinical course in Group P was evident at $10 \pm 2.12 \mathrm{~h}$ following the onset of propofol infusion and included a significant increase in serum lipid, GOT, GPT, LDH, total protein, total bilirubin, direct bilirubin, and CK levels (Table 2). A rapid drop in arterial pressure without a corresponding increase in heart rate followed these increases (Table 3), which may mean that the heart rate is more sensitivity to the effects of these drugs.

A significant increase $(P<0.05)$ in serum CK levels was observed, but total protein content, albumin and creatinine levels exhibited a significant decrease $12 \mathrm{~h}$ after the onset of isoflurane administration in Group I (Table 4). CK levels were significantly lower in Group I than in Group P $(P<0.05)$. Arterial blood pressure demonstrated a significant decrease in Group I at the termination of the experiment, but these values remained much higher than the levels in Group P.

Total protein content, total bilirubin, direct bilirubin, triglycerides, cholesterol, and CK gradually increased beginning at $12 \mathrm{~h}$ of infusion in Group II, and GOT, GPT, and LDH levels increased $24 \mathrm{~h}$ after infusion. Serum albumin levels decreased $12 \mathrm{~h}$ after the onset of $10 \%$ intralipid administration in isoflurane-sedated rabbits (Table 5). Triglycerides, CK levels and total protein content were significantly lower in Group II compared with Group P $(P<0.05)$. No deviations in vital signs were noted during the experiments, except for a decrease in systemic arterial pressure. However, systemic arterial pres- 
Table 2. Blood biochemical measurements in propofol-sedated rabbits. Mean \pm SD. $n=6 .{ }^{b} P<0.05$ when compared with pretreatment $(0 \mathrm{~h})$ values.

\begin{tabular}{|c|c|c|c|c|c|}
\hline \multirow[b]{2}{*}{ Variable } & \multicolumn{4}{|c|}{ Time (h) } & \multirow{2}{*}{$\begin{array}{c}\text { Reference } \\
\text { range }\end{array}$} \\
\hline & 0 & 12 & 24 & $30-36$ & \\
\hline Creatinine ( $\mu \mathrm{mol} / \mathrm{L})$ & $72.0 \pm 5.6$ & $61.1 \pm 6.2^{b}$ & $77.8 \pm 16.7$ & $86.8 \pm 22.2$ & $70-120$ \\
\hline GOT (U/L) & $20.0 \pm 4.9$ & $101.8 \pm 36.2^{b}$ & $166.8 \pm 65.6^{b}$ & $143.0 \pm 40.4^{b}$ & $<30$ \\
\hline GPT (U/L) & $45.3 \pm 12.2$ & $70.0 \pm 14.5^{b}$ & $180.0 \pm 45.0^{b}$ & $190.1 \pm 59.7^{b}$ & $<5-47$ \\
\hline LDH (U/L) & $242.3 \pm 34.4$ & $352.7 \pm 26.4^{b}$ & $455.5 \pm 20.5^{b}$ & $620.5 \pm 12.9^{b}$ & $243 \pm 50$ \\
\hline Total bilirubin $(\mu \mathrm{mol} / \mathrm{L})$ & $11.1 \pm 5.5$ & $144.4 \pm 8.6^{b}$ & $250.0 \pm 8.3^{b}$ & $227.8 \pm 12.1^{\mathrm{b}}$ & $<26$ \\
\hline Direct bilirubin ( $\mu \mathrm{mol} / \mathrm{L})$ & $5.6 \pm 2.1$ & $55.6 \pm 11.0^{b}$ & $77.8 \pm 11.1^{\mathrm{b}}$ & $44.4 \pm 11.0^{b}$ & $<7$ \\
\hline Cholesterol (mmol/L) & $3.98 \pm 2.4$ & $11.4 \pm 1.2^{b}$ & $19.3 \pm 2.8^{b}$ & $18.3 \pm 3.1^{\mathrm{b}}$ & $<5.2$ \\
\hline Triglycerides (mmol/L) & $3.7 \pm 1.1$ & $305.5 \pm 7.9^{b}$ & $451.2 \pm 114.1^{b}$ & $386.7 \pm 6.9^{b}$ & $<2.0$ \\
\hline $\mathrm{CK}(\mathrm{IU} / \mathrm{L})$ & $1059.3 \pm 383.0$ & $5842.0 \pm 3428.6^{b}$ & $8958.3 \pm 3645.1^{b}$ & $11389.7 \pm 7462.6^{b}$ & $50-1300$ \\
\hline
\end{tabular}

CK, creatine kinase; LDH, lactate dehydrogenase; GOT, glutamic oxaloacetic transaminase; GST, glutamic pyruvic transaminase.

Table 3. Hemodynamic data of mechanically ventilated rabbits sedated with propofol (Group P), isoflurane (Group I) and isoflurane while receiving intralipid (Group II). Mean \pm SD. $n=6$. ${ }^{b} P<0.05$ when compared with pretreatment $(0 \mathrm{~h})$ values; ${ }^{\mathrm{e}} P<0.05$ when compared with the same time-point values in Group P.

\begin{tabular}{|c|c|c|c|c|c|c|}
\hline \multirow[b]{2}{*}{ Variable } & \multicolumn{5}{|c|}{ Time (h) } & \multirow[b]{2}{*}{$30-36$} \\
\hline & 0 & 6 & 12 & 18 & 24 & \\
\hline \multicolumn{7}{|l|}{ Group P } \\
\hline AP syst (mmHg) & $90.5 \pm 13.5$ & $98.3 \pm 15.6$ & $81.6 \pm 12.3^{b}$ & $79.5 \pm 10.1^{\mathrm{b}}$ & $71.4 \pm 10.6^{b}$ & $33.2 \pm 4.4^{\mathrm{b}}$ \\
\hline AP diast (mmHg) & $60 \pm 19.3$ & $61.6 \pm 8.5$ & $53.6 \pm 5.2$ & $45.6 \pm 5.4$ & $44.3 \pm 5.6$ & $24.1 \pm 3.2^{b}$ \\
\hline AP mean $(\mathrm{mmHg})$ & $69.5 \pm 10.5$ & $73.1 \pm 11.3$ & $62.8 \pm 7.8$ & $56.3 \pm 7.3^{b}$ & $53.4 \pm 7.1^{b}$ & $26.8 \pm 3.8^{b}$ \\
\hline \multicolumn{7}{|l|}{ Group I } \\
\hline AP syst (mmHg) & $94.2 \pm 15.2$ & $94.3 \pm 13.4$ & $99.5 \pm 16.3$ & $95 \pm 12.5$ & $99.2 \pm 13.9$ & $87.6 \pm 10.5$ \\
\hline AP diast (mmHg) & $70.8 \pm 9.2$ & $65.1 \pm 8.2$ & $72.4 \pm 8.6$ & $70.1 \pm 7.6$ & $73.3 \pm 8.1$ & $55.3 \pm 4.7^{\text {be }}$ \\
\hline AP mean (mmHg) & $75 \pm 9.2$ & $67.8 \pm 8.3$ & $79.1 \pm 10.4$ & $78.4 \pm 8.7$ & $80.1 \pm 9.4$ & $65.2 \pm 7.1$ \\
\hline HR & $230.6 \pm 20.3$ & $232.8 \pm 16.1$ & $227 \pm 19.9$ & $228.6 \pm 18.9$ & $219.4 \pm 18.4$ & $216.2 \pm 14.5$ \\
\hline \multicolumn{7}{|l|}{ Group II } \\
\hline AP mean (mmHg) & $79.1 \pm 8.9$ & $77.6 \pm 7.1$ & $71.2 \pm 6.7$ & $73.1 \pm 6.7$ & $66.5 \pm 6.2^{\text {be }}$ & $57.5 \pm 5.6^{\text {be }}$ \\
\hline $\mathrm{HR}$ & $224.5 \pm 18.8$ & $223.5 \pm 14.9$ & $201.0 \pm 16.0$ & $208.8 \pm 17.8$ & $231.3 \pm 11.5$ & $219.8 \pm 13.2$ \\
\hline
\end{tabular}

$\mathrm{O}$ h=before intubation; AP, arterial blood pressure; HR, heart rate.

sure was significantly better than that in Group P.

\section{Histological findings}

The common characteristics of PRIS include cardiovascular collapse, cardiac arrhythmias, and metabolic acidosis ${ }^{[4,14]}$. Therefore, the morphological features of heart specimens were investigated to determine whether these features were consistent with the features of PRIS. The histological examination revealed little infiltration of acute inflammatory cells in the myocardial fibers in all 3 groups (data not shown). However, TNF-a signals were intensely positive in all heart samples of Group P, but TNF-a staining intensity was weak in Group II and negligent in Group I (Figure 1).

\section{Alterations in AMPK and phospho-AMPK expression in myo- cardial cells}

This study revealed an increased phosphorylation of AMPK at $\mathrm{Thr}^{172}$ in the heart following large doses of propofol infusion; little AMPK phosphorylation was observed in cardiac tissues of the other two groups (Figure 2).

\section{Discussion}

This study demonstrated that prolonged propofol sedation at high doses contributes to the incidence of fatal complica- 
Table 4. Blood biochemical measurements in isoflurane-sedated rabbits. Mean \pm SD. $n=6 .{ }^{b} P<0.05$ when compared with pretreatment $(0 \mathrm{~h})$ values. ${ }^{\text {e }} P<0.05$ when compared with the same time-point values in Group P.

\begin{tabular}{|c|c|c|c|c|c|}
\hline \multirow[b]{2}{*}{ Variable } & \multicolumn{4}{|c|}{ Time (h) } & \multirow{2}{*}{$\begin{array}{c}\text { Reference } \\
\text { range }\end{array}$} \\
\hline & 0 & 12 & 24 & $30-36$ & \\
\hline Creatinine ( $\mu \mathrm{mol} / \mathrm{L})$ & $72.2 \pm 5.6$ & $61.1 \pm 6.2^{b}$ & $50.0 \pm 7.8^{\text {be }}$ & $38.9 \pm 5.6^{\text {be }}$ & $70-120$ \\
\hline GOT (U/L) & $5.5 \pm 2.0$ & $25.0 \pm 3.3$ & $35.5 \pm 3.0$ & $31.5 \pm 6.0$ & $<30$ \\
\hline GPT (U/L) & $41.2 \pm 4.8$ & $45.0 \pm 3.2$ & $42.2 \pm 1.1$ & $46.0 \pm 9.1$ & $<5-47$ \\
\hline $\mathrm{LDH}(\mathrm{U} / \mathrm{L})$ & $236.5 \pm 90.5$ & $241.1 \pm 76.6$ & $253.3 \pm 152.2$ & $201.1 \pm 92.1$ & $243 \pm 50$ \\
\hline Total bilirubin $(\mu \mathrm{mol} / \mathrm{L})$ & $15.1 \pm 2.0$ & $14.4 \pm 8.6$ & $25.0 \pm 8.3$ & $27.8 \pm 12.1$ & $<26$ \\
\hline Direct bilirubin $(\mu \mathrm{mol} / \mathrm{L})$ & $5.1 \pm 0.5$ & $4.2 \pm 0.8$ & $5.9 \pm 1.1$ & $6.2 \pm 1.2$ & $<7$ \\
\hline Cholesterol (mmol/L) & $2.6 \pm 0.6$ & $1.9 \pm 0.4$ & $2.3 \pm 1.2$ & $3.9 \pm 1.1$ & $<5.2$ \\
\hline Triglycerides (mmol/L) & $2.6 \pm 0.5$ & $3.1 \pm 0.6$ & $2.8 \pm 1.1$ & $1.8 \pm 1.0$ & $<2.0$ \\
\hline CK (IU/L) & $1032.2 \pm 226$ & $3468.1 \pm 7965^{b}$ & $3548.2 \pm 1263^{\text {be }}$ & $3108.3 \pm 3746^{\text {be }}$ & $50-1300$ \\
\hline
\end{tabular}

CK, creatine kinase; LDH, lactate dehydrogenase; GOT, glutamic oxaloacetic transaminase; GST, glutamic pyruvic transaminase.

Table 5. Blood biochemical measurements in isoflurane-sedated rabbits receiving intralipid $10 \%$. Mean \pm SD. $n=6$. ${ }^{\mathrm{b}} P<0.05$ vs pretreatment $(0 \mathrm{~h})$ values. ${ }^{e} P<0.05$ vs the same time-point values in Group P.

\begin{tabular}{|c|c|c|c|c|c|}
\hline \multirow[b]{2}{*}{ Variable } & \multicolumn{4}{|c|}{ Time (h) } & \multirow{2}{*}{$\begin{array}{c}\text { Reference } \\
\text { range }\end{array}$} \\
\hline & 0 & 12 & 24 & $30-36$ & \\
\hline Creatinine ( $\mu \mathrm{mol} / \mathrm{L})$ & $77.7 \pm 5.6$ & $55.6 \pm 11.2^{\text {be }}$ & $44.5 \pm 5.6^{\text {be }}$ & $46.6 \pm 5.2^{\text {be }}$ & $70-120$ \\
\hline GOT (U/L) & $25.2 \pm 5.6$ & $35.6 \pm 9.5$ & $152.2 \pm 35.1^{\mathrm{b}}$ & $175.6 \pm 61.3^{b}$ & $<30$ \\
\hline GPT (U/L) & $38.5 \pm 12.5$ & $34.6 \pm 17.2$ & $195.2 \pm 37.6 b^{b}$ & $252 \pm 62.1^{\mathrm{b}}$ & $<5-47$ \\
\hline LDH (U/L) & $250.5 \pm 12.5$ & $215.4 \pm 32.6$ & $385.1 \pm 89.6^{b}$ & $575.1 \pm 124.2^{b}$ & $243 \pm 50$ \\
\hline Total protein $(\mathrm{g} / \mathrm{L})$ & $58.1 \pm 4.1$ & $75.1 \pm 1.2$ & $82.2 \pm 3.2^{\text {be }}$ & $133 \pm 4.1^{\text {be }}$ & $54-75$ \\
\hline Albumins (g/L) & $37.2 \pm 2.0$ & $29.2 \pm 2.1$ & $22.1 \pm 4.2^{b}$ & $24.2 \pm 1.0^{b}$ & $27-50$ \\
\hline Total bilirubin $(\mu \mathrm{mol} / \mathrm{L})$ & $11.1 \pm 5.6$ & $94.5 \pm 11.2^{\text {be }}$ & $248.9 \pm 105.2^{b}$ & $351.1 \pm 88.9^{\text {be }}$ & $<26$ \\
\hline Direct bilirubin $(\mu \mathrm{mol} / \mathrm{L})$ & $5.6 \pm 0.2$ & $55.6 \pm 16.7^{\mathrm{b}}$ & $100.1 \pm 22.3^{b}$ & $102.2 \pm 25.6^{\mathrm{be}}$ & $<7$ \\
\hline Cholesterol (mmol/L) & $3.4 \pm 0.2$ & $12.5 \pm 0.2^{b}$ & $19.2 \pm 6.3^{b}$ & $22.5 \pm 5.2^{b}$ & $<5.2$ \\
\hline Triglycerides (mmol/L) & $6.17 \pm 2.7$ & $31.6 \pm 1.2^{\text {be }}$ & $33.4 \pm 1.6^{\text {be }}$ & $35.2 \pm 2.2^{\text {be }}$ & $<2.0$ \\
\hline CK (IU/L) & $1006.1 \pm 1226$ & $3168.1 \pm 10965^{b}$ & $3328.2 \pm 1562^{\text {be }}$ & $3468.3 \pm 284.6^{\text {be }}$ & $50-1300$ \\
\hline
\end{tabular}

CK, creatine kinase; LDH, lactate dehydrogenase; GOT, glutamic oxaloacetic transaminase; GST, glutamic pyruvic transaminase.
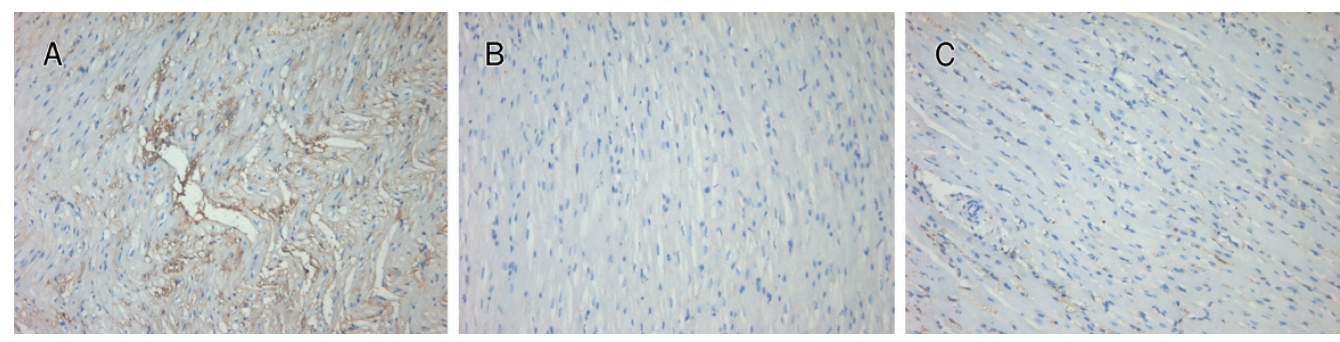

Figure 1. Immunohistochemical detection of tumor necrosis factor (TNF)- $\alpha$ in the heart. New Zealand rabbits under mechanically ventilation were subjected to sedation with $1 \%$ propofol (A), isoflurane (B) and isoflurane while receiving Intralipid 10\% (C), respectively, for $30-36 \mathrm{~h}$. Immunohistochemical detection of TNF- $\alpha$ with positive reaction in the propofol sedated heart (Brown reaction) $(n=6)$. Original magnification $\times 100$. Scale bar, $100 \mu \mathrm{m}$.

tions that resemble PRIS. This study also demonstrated that propofol produced an overexpression of TNF- $\alpha$ and AMPK activation, which has not been reported previously. The main features of PRIS include cardiovascular collapse, cardiac arrhythmias, and metabolic acidosis ${ }^{[4,14]}$. Rhabdomyolysis, hyperlipemia, and hypertriglyceridemia are other commonly 

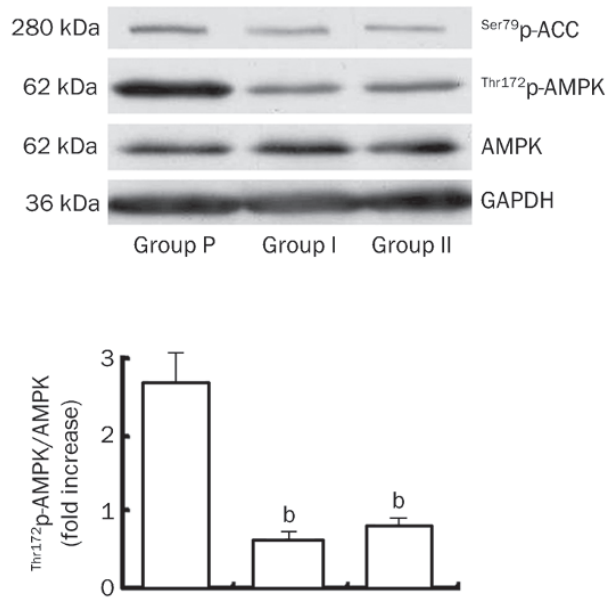

Figure 2. Immunoblot analysis of AMPK phosphorylation in the heart. New Zealand rabbits under mechanically ventilation were subjected to sedation with $1 \%$ propofol, isoflurane and isoflurane while receiving Intralipid 10\%, respectively, for 30-36 h. AMPK phosphorylation at Thr 172 in myocardial tissues was observed by immunoblot analysis with phosphospecific antibody. The data shown are mean \pm SD. $n=6 .{ }^{b} P<0.05$ vs propofol sedation.

described features, but these features are not consistently observed in all case reports and animal studies ${ }^{[15,16]}$. Cardiac failure, which is characterized by progressive bradycardia that leads to asystole, is the major cause of death in patients with PRIS ${ }^{[17]}$. Cardiac function in propofol-sedated animals in this study did not reveal any conduction defects or bradycardia during most of the experiment, except for a slight decrease in heart rate during the last $3-4 \mathrm{~h}$ of the experiment (220 \pm 13 and $187 \pm 9 \mathrm{beat} / \mathrm{min}$, at 0 and $30-36 \mathrm{~h}$, respectively). Histological examination did not demonstrate myofibril degeneration or rhabdomyolysis. Therefore, the negative signs of cardiac injury explicate the absence of terminal bradycardia, which is characteristic of PRIS in patients ${ }^{[3,17]}$. The immunohistochemical results demonstrated a strong positive reaction for TNF- $\alpha$ in propofol-infused cardiac myocytes, which indicated a rise in cardioinhibitory cytokines. The increase in TNF- $\alpha$ may be an adaptive response of a jeopardized myocardium ${ }^{[18]}$. Low- and high-dose propofol ( 1 and $10 \mathrm{mg} \cdot \mathrm{kg}^{-1} \cdot \mathrm{h}^{-1}$, respectively) exert beneficial effects on septic shock in rats and reduce serum TNF- $\alpha$ and IL-10 production after sepsis ${ }^{[19]}$. The difference between the results obtained here and these previous reports may be due to the administration of a long-term high-dose propofol infusion in this study; the use of high doses of propofol for prolonged periods is generally linked to a decrease in performance ${ }^{[3,15,17]}$. Cardiac arrhythmias, multiorgan damage, metabolic acidosis, rhabdomyolysis, hyperlipemia, and hypertriglyceridemia have been observed in critically ill patients receiving propofol for sedation ${ }^{[1-5]}$. However, the present study examined the effects of large doses of continuously infused propofol on lipid metabolism imbalance. Therefore, the primary outcome measurements in this study were blood biochemical deteriorations. The increases in LDH, GOT,
GPT, cholesterol, triglycerides and creatine kinase (CK) were greater in Group P compared to the intralipid group. More importantly, the increased concentrations of these parameters presented $12 \mathrm{~h}$ after propofol administration (Table 2). Therefore, clinicians in the ICU should be extremely suspicious of PRIS development when hyperlipidemia and abnormal indices of liver function are observed. Propofol should be discontinued immediately in these cases. The marked increase in triglyceride concentrations may be directly caused by an impaired $\beta$-oxidation of FFAs, which is induced by propofol, or by an altered mobilization of FFAs from triglycerides. An increase in sympathetic nervous system outflow and elevated cortisol and growth hormone concentrations, which are commonly observed in critically ill patients, may promote lipolysis and lipid oxidation, which further increase FFA concentrations ${ }^{[1]}$. Liver dysfunction due to circulatory failure or direct hepatotoxic effects of propofol may also adversely affect lipid kinetics. Lipemia alone impairs mitochondrial oxygen uptake, which contributes to the accelerated development and refractory nature of the PRIS. AMPK is activated during metabolic stress. AMPK activates a number of energy-producing metabolic pathways, but it also inhibits energy-consuming pathways ${ }^{[11]}$. AMPK has been termed a 'fuel gauge' for cellular energy levels because of this dual effect ${ }^{[9-12]}$. The role of AMPK as a fuel gauge is particularly relevant in the heart, which has a remarkably high demand for energy. In addition to its 'fuel gauge' role, AMPK influences apoptotic processes in eukaryotic cells, and the prolonged stimulation of AMPK induces apoptosis through c-Jun-N-terminal kinase activation ${ }^{[20]}$. The present study demonstrated that the continuous infusion of high-dose propofol induced AMPK activation. Whether the activation of AMPK is beneficial or harmful during PRIS is not known. Further studies to explore this potential are required.

Intralipid infusion in isoflurane-sedated rabbits under prolonged mechanical ventilation was performed to investigate the possible side effects of the lipid vehicle. No serious deviations in vital signs were observed, and all animals survived the 36-h study period. Histological examination revealed no inflammation of the heart, and immunohistochemistry revealed little TNF-a staining. These results demonstrated that the lipid solvent caused few catastrophic manifestations of PRIS, which is consistent with previous studies ${ }^{[16,21]}$.

Additionally, rabbits were mechanically ventilated under isoflurane sedation for the maximum survival period of the propofol-sedated rabbits. Therefore, prolonged mechanical ventilation did not contribute to the detrimental effects. Positive results have been observed when prolonged isoflurane sedation was used with an anesthetic-conserving device in critically ill patients ${ }^{[13]}$.

The present study included the following limitations. A more objective and sensitive method for the evaluation of sedation depth, such as the Bispectral Index or the electroencephalogram, would offer more precise adjustments of the sedative infusion rate or concentration. Additionally, the replication of human anesthetic dosing in rabbits was difficult. The initial propofol infusion rate was $10 \mathrm{mg} \cdot \mathrm{kg}^{-1} \cdot \mathrm{h}^{-1}$, and 
this dose was increased up to $65 \mathrm{mg} \cdot \mathrm{kg}^{-1} \cdot \mathrm{h}^{-1}$, which is disproportionally higher than PRIS in humans $\left(>4 \mathrm{mg} \cdot \mathrm{kg}^{-1} \cdot \mathrm{h}^{-1}\right)^{[4,22]}$. However, this result may explain the early onset of PRIS development in this species.

In summary, the continuous infusion of $1 \%$ propofol at large doses for sedation in rabbits undergoing prolonged mechanical ventilation induced detrimental changes in blood biochemistry, including hyperlipemia, liver dysfunction and a profound increase in CK levels, which indicated extended myocytolysis. These biochemical changes resembled PRIS. TNF-a expression increased in cardiac tissue specimens, which indicated myocardial injury. This observation that prolonged large doses of propofol infusion induce AMPK activation is novel. These results may provide a potential strategy for the elucidation of the mechanism of the imbalance between energy demand and utilization, which is a key pathogenetic mechanism in PRIS. The role of the lipid vehicle in the development of PRIS was minor, and this result was confined to late hyperlipidemia and liver dysfunction. Finally, isoflurane was a viable alternative sedation choice for prolonged mechanical ventilation in this rabbit model.

\section{Acknowledgements}

This study was supported by a grant from Shanghai Sixth Hospital.

\section{Author contribution}

Li WANG designed research and wrote the paper; Wei JIANG performed research; Zheng-bo YANG contributed equally to this work with Wei JIANG; Quan-hong ZHOU analyzed data; Xiang HUAN assisted to perform research.

\section{References}

1 Parke TJ, Stevens JE, Rice AS, Greenaway CL, Bray RJ, Smith PJ, et al. Metabolic acidosis and fatal myocardial failure after propofol infusion in children: five case reports. BMJ 1992; 305: 613-6.

2 Machata AM, Gonano C, Birsan T, Zimpfer M, Spiss CK. Rare but dangerous adverse effects of propofol and thiopental in intensive care. J Trauma 2005; 58: 643-5.

3 Riezzo I, Centini F, Neri M, Rossi G, Spanoudaki E, Turillazzi E, et al. Brugada-like EKG pattern and myocardial effects in a chronic propofol abuser. Clin Toxicol 2009; 47: 358-63.

4 Otterspoor LC, Kalkman CJ, Cremer OL. Update on the propofol infusion syndrome in ICU management of patient with head injury. Curr Opin Anaesthesiol 2008; 21: 544-51.

5 Wolf A, Weir P, Segar P, Stone J, Shield J. Impaired fatty acid oxidation in propofol infusion syndrome. Lancet 2001; 357: 606-7.
6 Marian M, Parrino C, Leo AM, Vincenti E, Bindoli A, Scutari G. Effect of the intravenous anesthetic 2,6-diisopropylphenol on respiration and energy production by rat brain synaptosomes. Neurochem Res 1997; 22: 287-92.

7 Branca D, Roberti MS, Vincenti E, Scutari G. Uncoupling effect of the general anesthetic 2,6-diisopropylphenol in isolated rat liver mitochondria. Arch Biochem Biophys 1991; 290: 517-21.

8 Schenkman KA, Yan S. Propofol impairment of mitochondrial respiration in isolated perfused guinea pig hearts determined by reflectance spectroscopy. Crit Care Med 2000; 28: 172-7.

9 Dyck JR, Lopaschuk GD. AMPK alterations in cardiac physiology and pathology: enemy or ally? J Physiol 2006; 574: 95-112.

10 Tsou P, Zheng B, Hsu CH, Sasaki AT, Cantley LC. A fluorescent reporter of AMPK activity and cellular energy stress. Cell Metab 2011; 13: 476-86.

11 Shirwany NA, Zou MH. AMPK in cardiovascular health and disease. Acta Pharmacol Sin 2010; 31: 1075-84.

12 Oakhill JS, Steel R, Chen ZP, Scott JW, Ling N, Tam S. AMPK is s direct adenylate charge-regulated protein kinase. Science 2011; 332: 1433-5.

13 Bradform MM. A rapid and sensitive method for the quantitation of microgram quantities of proteins utilizing the principle of protein dye binding. Analytical Biochem 1976; 72: 248-54.

14 Diedrich DA, Brown DR. Propofol Infusion syndrome in the ICU. J Intens Care Med 2011; 26: 59-72.

15 Fudickar A, Bein B. Propofol infusion syndrome: update of clinical manifestation and pathophysiology. Minerva Anestesiol 2009; 75: 339-44.

16 Ypsilantis P, Politou M, Mikroulis D, Pitiakoudis M, Lambropoulou M, Tsigalou C, et al. Organ toxicity and mortality in propofol-sedated rabbits under prolonged mechanical ventilation. Anesth Analg 2007; 105: 155-66.

17 Bray RJ. Propofol infusion syndrome in children. Paediatr Anaesth 1998; 8: 491-9.

18 Neri M, Bello S, Bonsignore A, Centini F, Fiore C, Földes-Papp Z, et al. Myocardial expression of TNF-alpha, IL-1beta, IL-6, IL-8, IL-10, and MCP-1 after a single MDMA dose administered in a rat model. Curr Pharm Biotechnol 2010; 11: 413-20.

19 Taniguchi T, Kanakura H, Yamamoto K. Effects of post-treatment with propofol on mortality and cytokine responses to endotoxin-induced shock in rats. Crit Care Med 2002; 30: 904-7.

20 Shaw RJ, Kosmatka M, Bardeesy N, Hurley RL, Witters LA, DePinho RA, et al. The tumor suppressor LKB 1 kinase directly activates AMP-activated kinase and regulates apoptosis in response to energy stress. Proc Natl Acad Sci U S A 2004; 101: 3329-35.

21 Ypsilantis P, Mikroulis D, Politou M, Tsoukali H, Pitiakoudis M, Didilis $\checkmark$, et al. Tolerance to propofol's sedative effect in mechanically ventilated rabbits. Anesth Anal 2006; 103: 359-65.

22 Fodale V, La Monaca E. Propofol infusion syndrome: an overview of a perplexing disease. Drug Saf 2008; 31: 293-303. 


\title{
Retraction: Lipid metabolism disturbances and AMPK activation in prolonged propofol-sedated rabbits under mechanical ventilation
}

Wei JIANG, Zheng-bo YANG, Quan-hong ZHOU, Xiang HUAN, Li WANG

\begin{abstract}
The authors are retracting their article entitled "Lipid metabolism disturbances and AMPK activation in prolonged propofolsedated rabbits under mechanical ventilation" [Acta Pharmacol Sin 2012; 33: 27-33]. Several expressions of this article were identical to those of previously published paper by Dr Petros YPSILANTIS et al [Anesth Analg 2007; 105: 155-66] and some original data were inappropriately manipulated. The authors would like to express their most sincere apology to Dr Petros YPSILANTIS and the Anesthesia \& Analgesia and to the editors and readers of Acta Pharmacologica Sinica.
\end{abstract}

